ISSN 1112-9867

\title{
A STUDY ON AIR POLLUTION CONCENTRATION AT DESA PARKCITY CONSTRUCTION SITE
}

\author{
A. S. M. Saudi ${ }^{1, *}$, M. Y. Nurulshyha ${ }^{1}$, M. Mahmud ${ }^{2}$ and Z. I. Rizman ${ }^{3}$ \\ ${ }^{1}$ Department of Environmental Healthcare, Institute of Medical Science Technology, \\ Universiti Kuala Lumpur, 43600 Kajang, Selangor, Malaysia \\ ${ }^{2}$ Department of Agribusiness and Bioresource Economics, Faculty of Agriculture, \\ UniversitiPutra Malaysia, Serdang, Selangor, Malaysia \\ ${ }^{3}$ Faculty of Electrical Engineering, UniversitiTeknologi MARA, 23000 Dungun, Terengganu, \\ Malaysia
}

Published online: 10 November 2017

\begin{abstract}
This study assesses the effect of construction workers exposure towards the air pollution to the correlation between meteorological factor with the particulate matter and other gases concentration at a construction site in DesaParkcity. The concentration of PM was collected by using low volume sampler meanwhile $\mathrm{CO}, \mathrm{CO}_{2}, \mathrm{SO}_{2}$ and $\mathrm{NO}_{2}$ was measured by Gas Alert Micro 5 IR. The meteorological factor was measured using an anemeter. The result shows that the average concentrations of PM10 are $62.71 \mu \mathrm{g} / \mathrm{m}^{3}$, concentration of PM2.5 is 18.32 $\mu \mathrm{g} / \mathrm{m}^{3}$ and concentration of PM1.0 is $14.04 \mu \mathrm{g} / \mathrm{m}^{3}$. PM10 shows the highest reading compared with PM2.5 and PM1.0. There is no significant association between meteorological factors with the particulate matter concentration. There is a significant association between meteorological factor with the concentration orCO, $\mathrm{CO}_{2}, \mathrm{SO}_{2}$ and $\mathrm{NO}_{2}$ at DesaParkcity construction site.
\end{abstract}

Keywords: air pollution; construction worker; meteorological factor.

Author Correspondence, e-mail: ahmadshakir@unikl.edu.my

doi: http://dx.doi.org/10.4314/jfas.v9i6s.44 


\section{INTRODUCTION}

Air pollution can be defined as the introduction of chemicals, particulate matter or biological materials that cause harm or discomfort to humans or other living organisms or cause damage to the natural environment or built environment into the atmosphere. World Health Organization (WHO) had recognized the main pollutant in the air are particulate matter, carbon monoxide, nitrogen dioxide, ozone, lead and sulphur dioxide [1]. Chemical compound present and they occur in unnaturally high concentration and have the potential to harm to the environment and human health [2].

Air pollution can occur indoor and outdoor. Outdoor air pollution often called that comes from car exhaust, smoke, road dust and factory emissions. Particle pollution can be high any time of year and are higher near busy roads and also large cities [3]. All large cities of the world are facing air pollution from motor vehicles and it had become a major problem for the physical and mental health of its citizens. The toxic chemical and gases release from vehicles emission produce irritation in the lung and air passage of the exposed population [4]. The two basic physical form or outdoor air pollutant are dust, smoke, sand, pollen, mist and fly ash. According to U.S Environmental Protection Agency (EPA), harmful gases include substances such as carbon monoxide $(\mathrm{CO})$, sulphur dioxide $\left(\mathrm{SO}_{2}\right)$, nitrogen dioxide $\left(\mathrm{NO}_{2}\right)$ and volatile organic compound [5].

One type of air pollution is the release of PM particles into the air from burning fuel for energy. The particles are very small pieces of matter measuring about 2.5 microns or about 0.0001 inches. This type of pollution is sometimes referred as black carbon pollution [6].

The gases exhaust from burning fuels in automobiles, homes and industries is a major source of pollution in the air. Some international authorities believe that even the burning of wood and charcoal in fireplaces and barbeques can release significant quantities of soot into the air [7]. Another type of pollution is the release of noxious gases, such as $\mathrm{SO}_{2}, \mathrm{CO}, \mathrm{NO}$ and chemical vapors. These gases can take part in further chemical reactions once they are in the atmosphere, forming smog and acid rain [8]. This paper will describe the particulate and other toxic gas content and their association with humidity and temperature at a construction site in DesaParkcity

\section{REVIEW OF LITERATURES}

The term particulate matter (PM) includes both solid particles and liquid droplets found in air. Many man-made and natural sources of air pollutant can directly emit gases and particles that can react in the atmosphere to form PM. The emission of solid and liquid particles can come 
in various sizes. Particles less than 2.5 micrometers in diameter are referred to as fine particles. Sources of fine particles include all types of combustion and some industrial processes [9].

Particles with diameters between 2.5 and 10 micrometers are referred to as coarse. Particles less than 10 micrometers in diameter tend to pose the greatest health concern because they can be easily inhaled and accumulate in the respiratory system [10].

Sources of coarse particles can come from the processing of crushing or grinding of bricks and dust from paved or unpaved roads. The Air Quality [17-25] Guidelines set for the first time a guideline value for particulate matter and the aim of the guidelines is to achieve the lowest concentrations of pollutant in atmosphere as possible [11].

PM becomes a great concern as it may affect the human health when exposed whether in short term or long term exposure. Particle pollution contains microscopic solids or liquid droplets that are so small that they can get deep into the lungs and cause serious health problems [12]. The size of particles is directly linked to their potential for causing health problems. Small particles less than 10 micrometers in diameter pose the greatest problems because they can get deep into your lungs and some may even get into your bloodstream [13].

\section{METHODOLOGY}

The study design for this study was a cross-sectional study. The concentration of Particulate matter (PM) and other gases was observed and recorded for 15 minutes for each time, three times per day. The concentration measurement takes places for a week from 25 th September 2012 to 2 nd October 2012.

The study was conducted at DesaParkcity construction site and the name of the project is The Mansion. The Mansion includes area of 19.6-acre site, which is located 200ft above sea level and lies slightly below the ParkCity Heights bungalows and $30 \mathrm{ft}$ to $40 \mathrm{ft}$ above the Casaman homes. It consists of 127 units of $2 \frac{1}{2}, 3$ and $3 \frac{1}{2}$-storey park homes. There will be 33 units of $2 \frac{1}{2}$-storey homes, 25 units of 3 -storey homes and 69 units of $3 \frac{1}{2} 2$-storey homes. The developer fir this construction site is Perdana Park city Construction Sdn Bhd. The duration of this construction site is from May 2011 until May 2014.

\subsection{Particulate Matter Measurements}

The concentration of PM of the location was collected by using low volume sampler meanwhile the concentration of other gases such as $\mathrm{CO}, \mathrm{CO}_{2}, \mathrm{SO}_{2}$ and $\mathrm{NO}_{2}$ was measured by Gas Alert Micro 5 IR. The readings of the PM were recorded for 15 minutes for each time, three times per day. 


\subsection{Meteorological Factor Measurement}

The anemometer is used to measure the meteorological factor such as the temperature and humidity at the construction site. The data was analyzed using SPSS software version 17. Results were presented through frequency outputs and other descriptive statistics.

\subsection{Data Analysis}

The data was analyzed using SPSS software version 17. Results were presented through frequency outputs and other descriptive statistics.

\section{RESULTS AND CONCLUSION}

\subsection{Particulate Matter Concentration}

Air pollution concentration in express in $\mu \mathrm{g} / \mathrm{m}^{3}$ (Table1). The reading of each day represent the 15 minutes recording at three predetermined point around the construction site. The result shows that the average concentrations of PM10 are $62.71 \mu \mathrm{g} / \mathrm{m}^{3}$, concentration of PM2.5 is $18.32 \mu \mathrm{g} / \mathrm{m}^{3}$ and concentration of PM1.0 is $14.04 \mu \mathrm{g} / \mathrm{m}^{3}$. Among the three particulate matter concentration, PM10 shows the highest reading compared with PM2.5 and PM1.0.

The particulate matter concentration has the highest level on day five and the lowest are on day two. For PM10 the highest reading is $153.62 \mu \mathrm{g} / \mathrm{m}^{3}$ and the lowest reading recorded are $14.56 \mu \mathrm{g} / \mathrm{m}^{3}$. For PM2.5, the highest reading is $32.47 \mu \mathrm{g} / \mathrm{m}^{3}$ meanwhile the lowest reading is $5.29 \mu \mathrm{g} / \mathrm{m}^{3}$. On the other hand, the highest concentration for PM1.0 is $21.37 \mu \mathrm{g} / \mathrm{m}^{3}$. PM1.0 and it was recorded lowest on the second day with a reading $4.22 \mu \mathrm{g} / \mathrm{m}^{3}$.

Table 1. Particulate matter concentration in $\left(\mu \mathrm{g} / \mathrm{m}^{3}\right)$

\begin{tabular}{cccc}
\hline Day & $\mathbf{P M}_{\mathbf{1 0}}$ & $\mathbf{P M}_{\mathbf{2 . 5}}$ & $\mathbf{P M}_{\mathbf{1 . 0}}$ \\
\hline 1 & 80.57 & 22.14 & 8.64 \\
2 & 14.56 & 5.29 & 4.22 \\
3 & 32.73 & 9.30 & 17.58 \\
4 & 69.16 & 23.67 & 19.02 \\
5 & 153.62 & 32.47 & 21.37 \\
6 & 35.94 & 24.85 & 22.57 \\
7 & 52.4 & 10.56 & 4.89 \\
Average & 62.71 & 18.32 & 14.04 \\
\hline
\end{tabular}


Table 2.Other pollutants concentration in ppm

\begin{tabular}{ccc}
\hline Day & $\mathbf{C O}_{\mathbf{2}}$ & $\mathbf{S O}_{\mathbf{2}}$ \\
\hline 1 & 550 & 0.3 \\
2 & 550 & 0.0 \\
3 & 316 & 0.2 \\
4 & 383 & 0.0 \\
5 & 300 & 0.0 \\
6 & 316 & 0.0 \\
7 & 300 & 0.2 \\
Average & 387 & 0.1
\end{tabular}

During the sampling the other air pollutants that are considered are $\mathrm{CO}_{2}, \mathrm{SO}_{2}, \mathrm{CO}$ and $\mathrm{NO}_{2}$. The average concentration for $\mathrm{CO}_{2}$ is $387 \mathrm{ppm}$. Meanwhile, the average concentration for $\mathrm{SO}_{2}$ is $0.1 \mathrm{ppm}$. However, there is no $\mathrm{CO}$ and $\mathrm{NO}_{2}$ concentration are recorded during the sampling duration of seven days. It clearly show that on day one and day two the concentration of $\mathrm{CO}_{2}$ was the same with a reading of 550ppm.It is the highest reading recorded among the seven day of sampling. The lowest concentration of $\mathrm{CO}_{2}$ is recorded on day five with the reading of $300 \mathrm{ppm}$.

The concentration of $\mathrm{SO}_{2}$ was only can be detected on day one, day three and day seven. However, no reading was recorder on day two, four, five and six. The concentration of $\mathrm{SO}_{2}$ on day one is $0.3 \mathrm{ppm}$, for the day three and day seven, the same amount of $\mathrm{SO}_{2}$ was detected that are $0.2 \mathrm{ppm}$.

During the sampling the other air pollutants that are considered are $\mathrm{CO} 2, \mathrm{SO}_{2}, \mathrm{CO}$ and $\mathrm{NO}_{2}$. The average concentration for $\mathrm{CO}_{2}$ is $387 \mathrm{ppm}$. Meanwhile, the average concentration for $\mathrm{SO}_{2}$ is $0.1 \mathrm{ppm}$. However, there is no $\mathrm{CO}$ and $\mathrm{NO}_{2}$ concentration are recorded during the sampling duration of seven days. It clearly show that on day one and day two the concentration of $\mathrm{CO}_{2}$ was the same with a reading of 550ppm, it is the highest reading recorded among the seven day of sampling. The lowest concentration of $\mathrm{CO}_{2}$ is recorded on day five with the reading of $300 \mathrm{ppm}$.

The concentration of $\mathrm{SO}_{2}$ was only can be detected on day one, day three and day seven. However, no reading was recorder on day two, four, five and six. The concentration of $\mathrm{SO}_{2}$ on day one is $0.3 \mathrm{ppm}$, for the day three and day seven, the same amount of $\mathrm{SO}_{2}$ was detected that are $0.2 \mathrm{ppm}$.

Temperature and humidity during the seven day of sampling at DesaParkcity construction site is shown in Table 3. The average temperature for the seven days is $30.9{ }^{0} \mathrm{C}$. The highest 
temperatures recorded are on day three and day five with the reading of $32.9^{0} \mathrm{C}$, meanwhile the lowest temperature that are recorder is on day two with the reading of $26.2{ }^{0} \mathrm{C}$. For the humidity, the average humidity that had been recorded for the seven day reading is 68.59 $\mathrm{kg} / \mathrm{m}^{3}$. The highest humidity was recorded on day two with the reading of $90 \mathrm{~kg} / \mathrm{m}^{3}$. Meanwhile, the lowest humidity was recorded on day five with the reading of $57.1 \mathrm{~kg} / \mathrm{m}^{3}$.

From Table 4, for the correlation significant of temperature with the air pollutant, there is no significant association between temperature and particulate matter as well as other gases as all the $\mathrm{p}$ value is greater than 0.05 . For the correlation between temperature and particulate matter, all the particulate matter shows positive correlation with the temperature. Therefore, it means that when temperature increases, there is an increasing concentration of particulate matter concentration. PM10 shows a fair positive correlation with temperature $(\mathrm{r}=0.45)$. Meanwhile, PM2.5 and PM1.0 show a weak positive correlation with the $r$ value 0.19 and 0.18 respectively.

$\mathrm{CO}_{2}$ shows a moderate negative correlation between $\mathrm{CO}_{2}$ with the temperature $(\mathrm{r}=-0.68)$. The temperature and $\mathrm{CO}_{2}$ are inversely proportional with each otherwhen the temperature increase, the concentration of $\mathrm{CO}_{2}$ will decrease and vice versa. For the temperature and $\mathrm{SO}_{2}$, there is a fair positive correlation relationship between temperature and $\mathrm{SO}_{2}$ with the $\mathrm{r}$ value of 0.42 . The temperature and $\mathrm{SO}_{2}$ are proportional with each other. When the temperature increases, the $\mathrm{SO}_{2}$ concentration will also increase.

All the result show there is no significant association between humidity and air pollutant as all the $\mathrm{p}$ value is more than 0.05 . However, there is a significant correlation between humidity and $\mathrm{CO}_{2}(\mathrm{r}=0.77, \mathrm{p}=0.03)$. PM10 shows negative moderate correlation with the temperature with the $\mathrm{p}$ value of -0.54 . PM2.5 shows a fair negative correlation with the temperature $(\mathrm{p}=$ -0.34) and PM1.0 shows a weak negative correlation with the temperature with the value of $p$ $=-0.25$. So, it can be concluded that the humidity are inversely proportional to the PM concentration. When the humidity increase, the concentration of PM will decrease or vice versa.

$\mathrm{CO}_{2}$ shows a strong positives correlation with the humidity with the value of $\mathrm{r}=0.77 . \mathrm{CO}_{2}$ are directly proportional with the humidity, the increasing of humidity will also increase the concentration of $\mathrm{CO}_{2}$ at the construction site. The $\mathrm{r}$ value for $\mathrm{SO}_{2}$ is -0.18 , so it can be concluded that $\mathrm{SO}_{2}$ have a weak negative correlation with the humidity. $\mathrm{The} \mathrm{SO}_{2}$ are inversely proportional with the humidity. When the humidity increase, the concentration of $\mathrm{SO}_{2}$ will also increase and vice versa.

From Table 5, it can be concluded there is no significant association between PM and other air 
pollutant as all the $\mathrm{p}$ value is greater than 0.05 . From the finding, it can be concluded that $\mathrm{CO}_{2}$ have a fair negative correlation with all type of PM10, PM2.5 and PM1.0 with the value of $-0.27,-0.42$ and -0.38 respectively. When the concentration of PM increase, the concentration of $\mathrm{CO}_{2}$ will decrease and vice versa.

For the $\mathrm{SO}_{2}$ with the $\mathrm{PM}$, it is a weak positive correlation with the $\mathrm{r}$ value equal to 0.12 . If the concentration of PM increases, the concentration of $\mathrm{SO}_{2}$ will also increase. On the other hand, for the PM2.5 and PM1.0 with $\mathrm{SO}_{2}$, it clearly shows that it has a fair negative correlation with the $r$ value of -0.35 and -0.41 . They are inversely proportional with each other.

From Table 5, it can be concluded that there is a significant correlation between PM10 and PM2.5 $(r=0.75, p=0.05)$. There is a significant correlation between PM2.5 and PM1.0 $(r=0.85$, $\mathrm{p}=0.01$ ). However, there is no significant correlation between particulate matters with other gases.

From Table 5, there is a strong positive correlation between PM10 and PM2.5 with the r value of 0.75. There is also a strong positive correlation between PM2.5 and PM1 ( $\mathrm{r}=0.85)$. Meanwhile, there is a fair correlation between PM10 and PM1.0. All the correlation are positive, so the PM are directly proportional with each other.When one of the PM increase, the other types of PM will also increases.

\subsection{DISCUSSION}

Table 1 shows that air pollution concentration in $\mu \mathrm{g} / \mathrm{m}^{3}$. The reading of each day represent the 15 minutes recording at three selected point around the construction site. The result shows that the average concentrations of PM10 are $62.71 \mu \mathrm{g} / \mathrm{m}^{3}$, concentration of PM2.5 is $18.32 \mu \mathrm{g} / \mathrm{m}^{3}$ and concentration of PM1.0 is $14.04 \mu \mathrm{g} / \mathrm{m}^{3}$. Among the three particulate matter concentration, PM10 shows the highest reading compared with PM2.5 and PM1.0. The PM concentration has the highest level on day five and the lowest are on day two. This result may be because on day five there is an extra worker that handling construction machinery and vehicles as the construction manager need to speed up the construction phase as instructed by the project initiator. On day five, there are two front loaders, three crane, three backhoes and two cement trucks. The temperature also play an important role in the reading of the PM at the construction site, as we can see the temperature on that day is the highest compared with the other days.

For PM10, the highest reading is $153.62 \mu \mathrm{g} / \mathrm{m}^{3}$ and the lowest reading recorded are 14.56 $\mu \mathrm{g} / \mathrm{m}^{3}$. For PM2.5, the highest reading is $32.47 \mu \mathrm{g} / \mathrm{m}^{3}$ meanwhile the lowest reading is 5.29 $\mu \mathrm{g} / \mathrm{m}^{3}$. On the other hand, the highest concentration for PM1.0 is $21.37 \mu \mathrm{g} / \mathrm{m}^{3}$ and it was 
recorded lowest on the second day with a reading $4.22 \mu \mathrm{g} / \mathrm{m}^{3}$. The lowest reading is on day two.This may be due to environmental factor as on that day the temperature and humidity are very low as it was raining in the morning. It causes the PM reading lower. This can be supported by a study that suggests temperature and humidity can affect the PM reading [14].

\subsection{Other Gases Concentrations}

During the sampling the other air pollutants that are considered is $\mathrm{CO}_{2}, \mathrm{SO}_{2}, \mathrm{CO}$ and $\mathrm{NO}_{2}$. The average concentration for $\mathrm{CO}_{2}$ is $387 \mathrm{ppm}$. Meanwhile, the average concentration for $\mathrm{SO}_{2}$ is $0.1 \mathrm{ppm}$. However, there is no $\mathrm{CO}$ and $\mathrm{NO}_{2}$ concentration are recorded during the sampling duration of seven days. The concentration of $\mathrm{CO}_{2}$ for the seven day of sampling clearly show that on day one and day two the concentration of $\mathrm{CO}_{2}$ was the same with a reading of $550 \mathrm{ppm}$, it is the highest reading recorded among the seven day of sampling. The lowest concentration of $\mathrm{CO}_{2}$ is recorded on day five with the reading of $300 \mathrm{ppm}$. The concentration of $\mathrm{SO}_{2}$ was only can be detected on day one, day three and day seven. However, no reading was recorder on day two, four, five and six. The concentration of $\mathrm{SO}_{2}$ on day one is $0.3 \mathrm{ppm}$.For the day three and day seven, the same amount of $\mathrm{SO}_{2}$ was detected that are $0.2 \mathrm{ppm}$.

\subsection{Temperature and Humidity}

Table 3 shows the temperature and humidity during the seven day of sampling at DesaParkcity construction site. The average temperature for the seven days are $30.9{ }^{0} \mathrm{C}$. The highest temperatures recorded are on day three and day five with the reading of $32.9{ }^{0} \mathrm{C}$, meanwhile the lowest temperature that are recorded is on day two with the reading of $26.2{ }^{0} \mathrm{C}$. For the humidity, the average humidity that had been recorded for the seven day reading is $68.59 \mathrm{~kg} / \mathrm{m}^{3}$. The highest humidity was recorded on day two with the reading of $90 \mathrm{~kg} / \mathrm{m}^{3}$. Meanwhile, the lowest humidity was recorded on day five with the reading of $57.1 \mathrm{~kg} / \mathrm{m}^{3}$. Temperature and humidity was recorded in order to study the correlation between meteorological factors with the air pollution concentration at DesaParkcity construction site.

From Table 4, for the correlation significant of temperature with the air pollutant, there is no significant association between temperature and particulate matter as well as other gases as all the $\mathrm{p}$ value is greater than 0.05 . For the correlation between temperature and particulate matter, all the particulate matter shows positive correlation with the temperature. Therefore, it means that when temperature increases, there is an increasing concentration of particulate matter concentration. PM10 show a fair positive correlation with temperature $(r=0.45)$, meanwhile PM2.5 and PM1.0 show a weak positive correlation with the $r$ value 0.19 and 0.18 respectively.

$\mathrm{CO}_{2}$ shows a moderate negative correlation between $\mathrm{CO}_{2}$ with the temperature $(\mathrm{r}=-0.68)$. 
The temperature and $\mathrm{CO}_{2}$ are inversely proportional with each other. When the temperature increase, the concentration of $\mathrm{CO}_{2}$ will decrease and vice versa. For the temperature and $\mathrm{SO}_{2}$, there is a fair positive correlation relationship between temperature and $\mathrm{SO}_{2}$ with the $\mathrm{r}$ value of 0.42 . The temperature and $\mathrm{SO}_{2}$ are proportional with each other. When the temperature increases, the $\mathrm{SO}_{2}$ concentration will also increase.

Table 4. Meteorological factor with all pollutant

\begin{tabular}{ccccc}
\hline Pollutant & \multicolumn{2}{c}{ Temperature } & \multicolumn{2}{c}{ Humidity } \\
& $\mathbf{r}$ & $\mathbf{p}$ & $\mathbf{r}$ & $\mathbf{p}$ \\
\hline $\mathrm{PM}_{10}$ & 0.45 & 0.31 & -0.54 & 0.21 \\
$\mathrm{PM}_{2.5}$ & 0.19 & 0.67 & -0.34 & 0.45 \\
$\mathrm{PM}_{1.0}$ & 0.18 & 0.69 & -0.25 & 0.58 \\
$\mathrm{CO}_{2}$ & -0.68 & 0.11 & 0.77 & $0.03^{*}$ \\
$\mathrm{SO}_{2}$ & 0.42 & 0.34 & -0.18 & 0.68
\end{tabular}

Table 5 shows that there is no significant association between humidity and air pollutant as all the $\mathrm{p}$ value is more than 0.05 . However, there is a significant correlation between humidity and $\mathrm{CO}_{2}(\mathrm{r}=0.77, \mathrm{p}=0.03)$. This can be supported by the study that had been done by [15-16].In [15] observed that carbon dioxide concentration show significantly positive correlation with humidity $(\mathrm{r}=0.647, \mathrm{p}<0.05)$.

PM10 shows negative moderate correlation with the temperature with the $p$ value of -0.54 . PM2.5 show a fair negative correlation with the temperature $(\mathrm{p}=-0.34)$ and PM1.0 shows a weak negative correlation with the temperature with the value of $p=-0.25$. So, it can be concluded that the humidity are inversely proportional to the PM concentration. When the humidity increase, the concentration of PM will decrease or vice versa.

$\mathrm{CO}_{2}$ shows a strong positives correlation with the humidity with the value of $\mathrm{r}=0.77 . \mathrm{CO}_{2}$ are directly proportional with the humidity.The increasing of humidity will also increase the concentration of $\mathrm{CO}_{2}$ at the construction site. The $\mathrm{r}$ value for $\mathrm{SO}_{2}$ is -0.18 , so it can be concluded that $\mathrm{SO}_{2}$ have a weak negative correlation with the humidity. The $\mathrm{SO}_{2}$ are inversely proportional with the humidity. When the humidity increase, the concentration of $\mathrm{SO}_{2}$ will also increase and vice versa. 
Table 5. Particulate matter with other gases $(n=7)$

\begin{tabular}{ccccccc}
\hline Pollutant & \multicolumn{2}{c}{$\mathbf{P M}_{10}$} & \multicolumn{2}{c}{$\mathbf{P M}_{2.5}$} & \multicolumn{2}{c}{$\mathbf{P M}_{1.0}$} \\
& $\mathbf{r}$ & $\mathbf{p}$ & $\mathbf{r}$ & $\mathbf{p}$ & $\mathbf{r}$ & $\mathbf{p}$ \\
\hline $\mathrm{PM}_{10}$ & & & 0.75 & 0.05 & 0.39 & 0.38 \\
$\mathrm{PM}_{2.5}$ & 0.75 & $0.05^{*}$ & & & 0.85 & $0.01^{*}$ \\
$\mathrm{PM}_{1.0}$ & 0.39 & 0.38 & 0.85 & $0.01^{*}$ & & \\
$\mathrm{CO}_{2}$ & -0.27 & 0.55 & -0.42 & 0.34 & -0.38 & 0.39 \\
$\mathrm{SO}_{2}$ & 0.12 & 0.79 & -0.35 & 0.43 & -0.41 & 0.35 \\
\hline
\end{tabular}

* Spearman correlation test was applied

*correlation is significant at 0.05 levels

The result shows that the average concentrations of PM10 are $62.71 \mu \mathrm{g} / \mathrm{m}^{3}$, concentration of PM2.5 is $18.32 \mu \mathrm{g} / \mathrm{m}^{3}$ and concentration of PM1.0 is $14.04 \mu \mathrm{g} / \mathrm{m}^{3}$. Among the three particulate matter concentration, PM10 shows the highest reading compared with PM2.5 and PM1.0. From the study, it can be concluded that there is no significant association between meteorological factors with the particulate matter concentration at DesaParkcity construction site. Thus, the hypothesis is rejected.

There is no significant association between temperature and particulate matter, as well as other gases. For the correlation between temperature and particulate matter, all the particulate matter shows significant association with the temperature. Therefore, it means that when temperature increases, there is an increasing concentration of particulate matter concentration. For the correlation significant of humidity and air pollutant, there is a significant association between meteorological factor with the concentration or $\mathrm{CO}_{2}, \mathrm{CO}, \mathrm{SO}_{2}$ and $\mathrm{NO}_{2}$ at DesaParkcity construction site. This hypothesis is accepted for carbon dioxide association with humidity. There is a significant correlation between humidity and $\mathrm{CO}_{2}(\mathrm{r}=0.77$, $\mathrm{p}=0.03$ ). There is no significant association between particulate matter concentrations with other gases at DesaParkcity Construction site.

\section{ACKNOWLEDGEMENTS}

The authors would like to thank Ministry of Higher Education (MOHE), Malaysia for granting Fundamental Research Grant Scheme (FRGS) to undertake the study for the period of 2 years (November 2010-present). 


\section{REFERENCES}

[1] World Health Organization (WHO). Air quality guidelines. Geneva: WHO, 1999

[2] Sufian M. Airborne nitrogen dioxide composition and its genotoxicity. Arch International Medical, 2011, 163:205-209

[3] Cohen AJ. Outdoor air pollution and lung cancer. Environmental Health Perspective, 2000, 108:743-750

[4] Pal P, Robert A J, Dutta T K, Pal G K. Pulmonary function test in traffic police personnel in Pondicherry. Indian Journal of Physiology and Pharmacology, 2010,54(4): 329-336

[5] United States Environmental Protection Agency (USEPA). National primary and secondary ambient air quality standards-Code of federal regulations Title 40 part 58 . Washington DC: USEPA, 1999

[6] Williams D S, Shukla M K, Ross J. Particulate matter emitted by a vehicle running on unpaved road. Atmospheric Environment, 2008, 42(16):3899-3905

[7] Vouitsis E, Ntziachristos L, Pistikopoulos P, Samaras Z, Chrysikou L, Samara C, Papadimitriou C, Samaras P, Sakellaropoulos G. An investigation on the physical, chemical and ecotoxicological characteristics of particulate matter emitted from light-duty vehicles. Environmental Pollution, 2009, 157(8):2320-2327

[8] Shi J P, Evans D E, Khan A A, Harrison R M. Sources and concentration of nanoparticles (< 10nm diameter) in the urban atmosphere. Atmospheric Environment, 2001, 35(7):1193-1202

[9] Eleftheriadis K, Diapouli E, Gini MI, Vasilatou V, Samara C, Argyropoulos G. Source apportionment of airborne particulate matter for three urban centres in Greece. InEuropean Aerosol Conference, 2011, pp. 4-9

[10] Laden F, Neas L M, Dockery D W, Schwartz J. Association of fine particulate matter from different sources with daily mortality in six US cities. Environmental Health Perspectives, 2000, 108(10):941-947

[11] World Health Organization (WHO). Air quality guidelines for particulate matter, ozone, nitrogen dioxide and sulfur dioxide: Global update 2005-Summary of risk assessment.Copenhagen: WHO, 2010

[12]Pope III C A, Dockery D W. Health effects of fine particulate air pollution: Lines that connect. Journal of the Air and Waste Management Association, 2006, 56(6):709-742

[13]Klemm R J, Mason Jr R M, Heilig C M, Neas L M, Dockery D W. Is daily mortality associated specifically with fine particles? Data reconstruction and replication of analyses. Journal of the Air and Waste Management Association, 2000, 50(7):1215-1222 
[14]Miranda R, Tomaz E. Characterization of urban aerosol in Campinas, São Paulo, Brazil. Atmospheric Research, 2008, 87(2):147-157

[15]Indira T K, Lakshmi P K. Magnetic nanoparticles-A review. International Journal of Pharmaceutical Sciences and Nanotechnology, 2010, 3(3):1035-1042

[16]Fang J, Guo Z, Piao S, Chen A. Terrestrial vegetation carbon sinks in China, 1981-2000. Science in China Series D: Earth Sciences, 2007, 50(9):1341-1350

[17] Shafii N Z, Saudi A S, Mahmud M, Rizman Z I. Spatial assessment on ambient air quality status: A case study in Klang, Selangor. Journal of Fundamental and Applied Sciences, 2017, 9(4S):964-977

[18]Hanapiah S M, Saudi A S, Rizman Z I. Assessment on pattern of urban air quality by using chemometric technique: A case study in Kota Kinabalu, Sabah. Journal of Fundamental and Applied Sciences, 2017, 9(4S):861-870

[19]Masyita M, Amalina M J, Saudi A S, Samsudin M S, Rizman Z I. Effect of poster and video intervention on the knowledge, attitude and practice (KAP) level of personal hygiene among food handlers in 24 hours Mamak restaurants in Sungai Petani, Kedah.Journal of Fundamental and Applied Sciences, 2017, 9(4S):851-860

[20] Saudi A S, Ridzuan I S, Balakrishnan A, Azid A, Shukor D M, Rizman Z I. New flood risk index in tropical area generated by using SPC technique.Journal of Fundamental and Applied Sciences, 2017, 9(4S):828-850

[21] Sarijuddin F A, Saudi A S, Kamarudin M K, Isa K N, Mahmud M, Azid A, Balakrishnan A, Abu I F, Amin N A, Rizman Z I. Assessment on level of indoor air quality at kindergartens in Ampang Jaya, Selangor, Malaysia.Journal of Fundamental and Applied Sciences, 2017, 9(4S):801-811

[22]Kamaruzzaman A, Saudi AS, Azid A, Balakrishnan A, Abu IF, Amin NA, Rizman ZI. Assessment on air quality pattern: A case study in Putrajaya, Malaysia.Journal of Fundamental and Applied Sciences, 2017, 9(4S):789-800

[23]Zakaria U A, Saudi A S, Abu I F, Azid A, Balakrishnan A, Amin N A, Rizman Z I. The assessment of ambient air pollution pattern in Shah Alam, Selangor, Malaysia.Journal of Fundamental and Applied Sciences,2017, 9(4S):772-788

[24]Kamarudin MK, Nalado AM, Kasmuri A, Toriman ME, Juahir H, Umar R, Jamil NR, Saudi AS, Rizman ZI, Gasim MB, Hassan AR. Assessment of river plan changes in Terengganu River using RS and GIS method.Journal of Fundamental and Applied Sciences, 2017, 9(2S):28-45 
[25] Saudi A S, Kamarudin M K, Ridzuan I S, Ishak R, Azid A, Rizman Z I. Flood risk index pattern assessment: Case study in Langat River Basin.Journal of Fundamental and Applied Sciences, 2017, 9(2S):12-27

How to cite this article:

Saudi A S M, Nurulshyha M Y, Mahmud M, Rizman Z I. A study on air pollution concentration at desa parkcity construction site. J. Fundam. Appl. Sci., 2017, 9(6S), 587-599. 